\title{
JASA LINGKUNGAN TAMAN KEANEKARAGAMAN HAYATI (KEHATI) BADAN LINGKUNGAN HIDUP DI KABUPATEN SEKADAU TAHUN 2017
}

\author{
(Environmental Services of Hayati Diversity Park (Kehati) Environmental Agency in Sekadau \\ District 2017)
}

\author{
Desiana, Emi Roslinda, Siti Masitoh Kartikawati \\ Fakultas Kehutanan Universitas Tanjungpura Pontianak. J1. Daya Nasional Pontianak 78124 \\ E-mail : desianaar@gmail.com
}

\begin{abstract}
Environmental services are the services provided by the ecosystem functions that have direct and indirect benefits. The purpose of this study is to describe the potential of environmental services in the KEHATI Park, Sekadau Regency. KEHATI Park Sekadau was built in 2012 with the aim of adding green open space land cover, collection of plants, development of science and ecotourism and the sources of seeds. The KEHATI Park ecosystem in Sekadau Regency has the potential of environmental services as a result of the interaction of the ecosystem in it. The Millennium Ecosystem Assessment (MEA 2005) classifies environmental services into four namely provisioning services, regulating services, cultural services, and supporting services. The method used is the survey method with interview techniques and questionnaires. For sampling of respondents conducted by accidental sampling and census. Data analysis was conducted based on MEA (2005) which was then analyzed descriptively. The environmental services contained in the Sekadau Forest Park are potential provisioning services that can be seen from foodstuffs such as fruit plants, medicines, vegetables, and forestry plants. Then regulating services that have the function of maintaining air quality, cultural services which are non-material benefits as a place of recreation, and the existence of supporting services (supporting services).
\end{abstract}

Keywords: Environmental Services, KEHATI Park Sekadau, Millenium Ecosystem Assesment

\section{PENDAHULUAN}

Indonesia adalah negara yang memiliki kekayaan keanekaragaman hayati yang berlimpah. Berlimpahnya kekayaan alam ini dapat digunakan untuk menunjang kehidupan dan mensejahterakan rakyatnya. Usaha pemanfaatan sumberdaya alam banyak menyebabkan terjadinya kerusakan lingkungan yang dapat menurunkan keanekaragaman hayati Indonesia. Salah satu untuk mencegah terjadinya kepunahan keanekaragaman hayati yaitu dibangun Taman Keanekaragaman Hayati (KEHATI).

Indonesia terdapat sepuluh lokasi Taman KEHATI diantaranya tedapat di wilayah Provinsi Sumatera di areal arboretum Universitas Andalas dengan luas areal sekitar 15 Ha. Taman KEHATI Kabupaten Belitung dengan luas lahan taman kehati 16,25 Ha. Taman KEHATI Kabupaten Lampung Barat dengan luas 15 Ha. Taman KEHATI Kabupaten Kuningan dengan luas 4,3 Ha. Taman KEHATI Daerah Istimewa Yogyakarta yaitu berada di Kabupaten Gunung kidul, terbagi dalam 3 (tiga) lokasi terpisah yaitu satu di Kecamatan Ngawen, dan dua di Kecamatan Tepus, dengan total luas lokasi Taman KEHATI yaitu 15 Ha. Taman KEHATI Kabupaten Jombang, taman KEHATI Provinsi Jawa Timur dengan 
luasan sekitar 15 Ha. Taman KEHATI Kabupaten Sekadau, yang berada di komplek perkantoran Pemerintah Kabupaten (Pemkab) Sekadau - Sintang KM 9, Desa Bokak Sebumbum. dengan luas Taman KEHATI sekitar 25 Ha. (KLHK, 2015).

Jasa Ekosistem dapat dikelompokkan menjadi empat yaitu: (1) Jasa Penyediaan (Provisioning services), produk yang berasal dari ekosistem, seperti makanan, air, bahan bakar, serat, dan lain-lain, (2) Jasa Pengaturan (Regulating services), manfaat yang diperoleh dari peraturan ekosistem proses, seperti pemeliharaan kualitas udara, peraturan iklim, pengelolaan air, pengendalian banjir, regulasi penyakit manusia, dan lain-lain, (3) Jasa Budaya (Cultural services), manfaat non-material yang diperoleh dari ekosistem, seperti keragaman budaya, nilai spiritual dan agama, nilai pendidikan, inspirasi, nilai estetika, hubungan sosial, peninggalan pusaka, rekreasi dan lain-lain, dan (4) Jasa Pendukung (Supporting services), layanan yang dibutuhkan untuk menghasilkan Jasa Ekosistem lainnya, seperti pembentukan tanah, ketersediaan habitat, siklus nutrisi, produksi primer, dan lain-lain. (MEA, 2005).

Jasa lingkungan adalah produk sumber daya alam hayati dan ekosistemnya yang berupa manfaat langsung (tangible) dan atau manfaat tidak langsung (intangible). Contoh-contoh jasa lingkungan adalah jasa wisata alam, jasa perlindungan tata air (hidrologi), kesuburan tanah, pengendalian erosi dan banjir, keindahan dan keunikan alam, penyerapan dan penyimpanan karbon (carbon offset). Jasa lingkungan juga dihasilkan dari berbagai jenis penggunaan lahan (hutan atau pertanian), perairan baik air tawar (sungai, danau, rawa) maupun laut (Soearno, 2014).

Taman KEHATI Sekadau di bangun dengan tujuan untuk penambahan tutupan lahan ruang terbuka hijau, koleksi tumbuhan, pengembangan ilmu pengetahuan dan ekowisata serta sumber bibit dan benih. Pembangunan taman KEHATI diharapkan bisa mendukung konservasi flora dan fauna di luar kawasan hutan sehingga mampu meningkatkan keanekaragaman hayati khususnya di Kabupaten Sekadau. Meningkatnya KEHATI mengandung berbagai potensi jasa ekosistem (ecosystem services) yang bermanfaat bagi kehidupan. Sejak pembangunan sampai saat ini belum ada informasi mengenai potensi jasa lingkungan yang terkandung di taman KEHATI Sekadau, maka perlu dilakukan penelitian mengenai potensi jasa lingkungan yang terdapat di taman KEHATI Sekadau. Penelitian bertujuan untuk mendeskripsikan jasa lingkungan yang ada di taman KEHATI Kabupaten Sekadau.

\section{METODE PENELITIAN}

Lokasi penelitian berada di taman KEHATI Kabupaten Sekadau Provinsi Kalimantan Barat yang terletak di Desa Bokak Sebumbun, Kecamatan Sekadau Hilir. Penelitian ini dilaksanakan pada bulan Agustus-September 2017. Objek dalam penelitian ini adalah pengunjung yang sedang berkunjung ke taman KEHATI dan pihak pengelola taman. Pengambilan sampel responden yaitu pengunjung dilakukan secara accidental 
sampling (sugiyono, 2013), sedangkan pihak pengelola taman dilakukan secara sensus. Metode yang digunakan adalah metode survey dengan teknik wawancara dan kuisioner. Jumlah responden sebagai sampel penelitian sebanyak 58 responden yang terdiri atas pengelola dan masyarakat yang berkunjung ke taman KEHATI.

\section{HASIL DAN PEMBAHASAN}

\section{Karakteristik Responden}

Responden dalam penelitian ini adalah pengunjung atau wisatawan lokal yang berkunjung ke taman KEHATI.
Berdasarkan data 58 responden yang berkunjung ke taman KEHATI Sekadau, melalui daftar pertanyaan didapat karakteristik responden yang digolongkan ke dalam beberapa aspek diantaranya adalah: daerah asal responden, jenis kelamin, umur, status pernikahan, pendidikan terakhir, pekerjaan responden, pendapatan atau penghasilan responden dan tujuan berkunjung.

Penggolongan beberapa aspek responden sebagai obyek penelitian tersebut dapat dilihat pada tabel 1 .

\section{Tabel 1. Karakteristik Responden Taman KEHATI (Characteristics of KEHATI}

Park Respondents)

\begin{tabular}{lc}
\hline \multicolumn{1}{c}{ Karakteristik Responden } & Persentase (\%) \\
\hline 1. alamat/daereah asal : & \\
a. Kec.Sekadau Hilir & 98,28 \\
b. Kec. Belitang Hilir & 1,72 \\
\hline 2. Jenis Kelamin & \\
a. laki-laki & 56,90 \\
b. perempuan & 43,10 \\
\hline 3. Umur & 18,97 \\
a. $<17$ & 70,69 \\
b. $17-25$ & 5,17 \\
c. $26-35$ & 5,17 \\
d. $>35$ & \\
\hline 4. Status pernikahan & 15,52 \\
a. sudah menikah & 84,48 \\
b. belum menikah & \\
\hline 5. Pendidikan & 34,48 \\
a. SMP & 53,45 \\
b. SMA & 12,07 \\
c. Perguruan Tinggi & \\
\hline 6. Pekerjaan & 17,24 \\
a. petani & 1,72 \\
b. pegawai negeri & 6,90 \\
c. pegawai swasta & 6,90 \\
d. honorer & 5,17 \\
e. pedagang & 62,07 \\
f. pelajar & \\
\hline 7. Pendapatan & 87,50 \\
a. $<1.000 .000$ & 8,33 \\
b. 1.000.000-2.000.000 & 2,08 \\
c. 2.000.000-3000.000 & 2,08 \\
d. 3000.000-4.000.000 & \\
\hline 8. Tujuan berkunjung & 90,63 \\
a. rekreasi, fotografi dan berpetualang & 9,38 \\
b. lain-lain &
\end{tabular}


Data di atas menunjukan persentase tertinggi daerah asal pengunjung yaitu bersal dari Kecamatan Sekadau hilir, hal ini dikarenakan pengunjung yang berkunjung masih didominasi oleh masyarakat sekitar kawasan taman KEHATI yang lebih mengetahui informasi lokasi taman ini dan jarak yang lebih terjangkau. Pengunjung lebih didominasi oleh laki-laki hal ini dikarenakan mereka lebih menyukai petualangan dan didukung oleh pemandangan alam yang terdapat di taman tersebut. Berdasarkan persentase di atas diketahui umur pengunjung terbanyak terdapat pada rentang umur 17-25 tahun yaitu sebanyak 70,69\%. Hal ini karena pada umur remaja memiliki waktu luang dan rasa ingin tahu yang begitu besar untuk melakukan kegiatan rekreasi.

Responden sebanyak $84,48 \%$ yang belum menikah sedangkan yang sudah menikah hanya sebanyak $15,52 \%$. Hal ini karena pengunjung yang belum menikah mempunyai banyak kesempatan untuk melakukan kegiatan rekreasi. Sementara responden yang sudah menikah mempunyai kesibukan misalnya disibukkan dengan aktivitas dalam rumah tangga. Pendidikan terakhir responden, persentase pengunjung terbanyak pada tingkat pendidikan SMA yaitu sebanyak 53,45\%. Hal ini dikarenakan pada tingkat pendidikan tersebut masih mempunyai keinginan besar untuk bersenang-senang dan karena semakin maraknya atau semakin modernnya suatu perjalanan menuju tempat-tempat rekreasi. Berdasarkan profesi responden yang berkunjung yang mendominasi adalah pelajar atau mahasiswa sebanyak 62,07\%. Hal ini karena pelajar biasanya ingin menghabiskan waktu berkumpul dan bersenang-senang untuk menghilangkan kepenatan atau kebosanan dengan aktivitas sehari-hari sebagai seorang pelajar atau mahasiswa. Berdasarkan pekerjaan pengunjung maka akan diketahui juga berapa pendapatan responden dalam satu bulan. Pendapatan atau uang saku dengan persentase terbanyak adalah $<1.000 .000$, hal ini dikarenakan mayoritas yang berkunjung adalah pelajar. Berdasarkan data yang terkumpul diketahui bahwa mayoritas responden menyatakan tujuan mereka berkunjung adalah untuk rekreasi, fotografi dan berpetualang. Hal ini merupakan tujuan umum wisatawan yang berkunjung ke tempat rekreasi.

\section{Potensi Jasa Lingkungan Taman KEHATI \\ Potensi Penyedian (Provisioning Services) \\ Potensi penyediaan (provisioning} services), berupa sumber bahan makanan, obat-obatan alamiah, sumberdaya genetik, kayu bakar, serat, air, mineral dan lain-lain. Potensi penyediaan yang terdapat di taman KEHATI Sekadau dapat dilihat dari manfaat flora yang ada di taman KEHATI tersebut, baik itu berpotensi sebagai bahan makanan, bahan bangunan, obat-obatan dan lain-lain. Ringkasan beberapa tumbuhan di taman KEHATI yang memiliki potensi penyediaan dapat dilihat pada Tabel 2 . 
Tabel 2. Pemanfaatan Jenis Tanaman Di Taman KEHATI (Utilization of Plant Types in the KEHATI Park)

\begin{tabular}{ccccccc}
\hline & & \multicolumn{5}{c}{ Kegunaan } \\
\cline { 3 - 7 } No & Jenis & $\begin{array}{c}\text { Bahan } \\
\text { makanan } \\
(\mathbf{\%})\end{array}$ & $\begin{array}{c}\text { Obat- } \\
\text { obatan } \\
(\mathbf{\%})\end{array}$ & $\begin{array}{c}\text { Bahan } \\
\text { bangunan } \\
\mathbf{( \% )}\end{array}$ & $\begin{array}{c}\text { Kayu bakar } \\
\mathbf{( \% )}\end{array}$ & $\begin{array}{c}\text { Lain-lain } \\
(\mathbf{\%})\end{array}$ \\
\hline & $\begin{array}{c}\text { Persentase } \\
(\%)\end{array}$ & 51,786 & 10,996 & 23,590 & 5,451 & 8,177 \\
\hline
\end{tabular}

Tabel 2 menunjukkan jumlah pemanfaatan tertinggi yaitu digunakan sebagai makanan $51,786 \%$, terdiri atas tanaman durian (Durio zibethinus), petai (Parkia speciosa hassk), rambutan (Nephelium lappaceum L), mentawa (Artocarpus anisophyllus), jengkol (Pithellocobium lobatum benth), mangga (Daecryodes rostata), langsat (Lansium domesticum), jeruk manis (Citrus $x$ sinensis), jambu biji (Psidium guajava L), jeruk nipis (Citrus grandis), jambu air (Eugenia aquea), nangka (Artocarpus heterophyllus), cempedak (Artocarpus intiger), lengkuas (Kaempferia galanga), kunyit (Curcuma longa), pekawai, dan kemantan. Penelitian Firdaus (2011) di Desa Meragun Nanga Taman Kabupaten Sekadau menemukan 73 jenis tumbuhan yang berpotensi sebagai sumber pangan tercatat dalam kelompok buah-buahan 34 spesies $(46,15 \%)$, kelompok sayursayuran 33 spesies (46,15\%), kelompok jamur-jamuran 2 spesies (2,56 \%), kelompok umbi-umbian 2 spesies $(2,56$ $\%$ ), dan kelompok tebu-tebuan 2 spesies $(2,56 \%)$.

Potensi pemanfaatan untuk obatobatan sebesar 10,996\%, dengan jenisjenis tanaman yaitu langsat (Lansium domesticum), jambu biji (Psidium guajava L), jeruk nipis (Citrus grandis), lengkuas (Kaempferia galanga), kunyit (Curcuma longa), temu lawak (Curcuma xanthoorrhiza roxb), dan lempuyang (Zingeirber zerumbet linn). Sebagai contoh yaitu tanaman langsat yang merupakan salah satu dari tanaman obat, penduduk Kalimantan menggunakan biji buah langsat sebagai penurun demam, bijinya dimanfaatkan sebagai obat cacing, obat demam dan obat mencret. Kulit kayunya digunakan untuk mengobati disentri dan malaria. Kulit buah langsat yang dikeringkan digunakan sebagai antidiare dan antikolik. Berbagai pemanfaatan tanaman ini sebagai obat tradisional, khususnya sebagai obat disentri mengindikasikan bahwa langsat memiliki aktivitas antibakteri (Siahaan, 2013).

Potensi pemanfaatan untuk bahan bangunan sebesar $23,590 \%$, yang terdiri atas tanaman durian (Durio zibethinus), ubah (Calophyllum soulattri), bintangur, tengkawang (Shorea stenoptera), bengkirai (Shorea laevis ridl), laban (Vitex pinnata), pulai (Alstonia scholaris), kemantan, dan belian (Eusideroxylon zwageri). Jenis-jenis 
tanaman tersebut merupakan jenis kayu pada umumnya yang digunakan sebagai bahan bangunan seperti tanaman ulin (Eusideroxylon zwageri). Hasil penelitian diketahui bahwa seluruh responden menganggap pohon ulin pada bagian batang sangat berfungsi sebagai bahan bangunan. Larasati (2017) menyatakan kayu belian (ulin) merupakan kayu yang cocok untuk bahan bangunan karena sangat awet dan kuat serta memiliki nilai ekonomi yang tinggi. Penelitian Irsyad, et al (2013) tercatat ada sekitar 29 jenis tumbuhan kayu yang digunakan sebagai bahan bangunan rumah bagi masyarakat sukolilo.

\section{Potensi Jasa Pengaturan (Regulating} Services),

Jasa pengaturan yang dimaksud disini adalah jasa lingkungan memiliki fungsi untuk menjaga kualitas udara yang ada di kawasan tersebut. Pengaturan kualitas udara tersebut dapat diperoleh karena terdapat tumbuhan dan pepopohan yang mampu menyediakan udara segar bagi lingkungan sekitar. Guna mengetahui potensi pengaturan ditaman KEHATI maka responden diminta untuk menjawab beberapa pertanyaan yang disajikan pada Tabel 3.

Tabel 3. Tabel Jawaban Responden Untuk Potensi Pengaturan (Respondents Answer Tables for Potential Settings )

\begin{tabular}{|c|c|c|c|c|}
\hline \multirow[t]{2}{*}{ No. } & \multirow[t]{2}{*}{ Pertanyaan } & \multicolumn{2}{|c|}{ Jawaban } & \multirow{2}{*}{$\begin{array}{c}\text { Jumlah } \\
(\%)\end{array}$} \\
\hline & & $\mathrm{Ya}$ & Tidak & \\
\hline 1. & $\begin{array}{l}\text { Dilihat dari tegakan tumbuhan apakah taman KEHATI dapat } \\
\text { menyimpan air? }\end{array}$ & 94,82 & 5,18 & 100 \\
\hline 2. & $\begin{array}{l}\text { Berdasarkan aliran sungai kecil, kolam dan sumur apakah taman } \\
\text { KEHATI mempu menyediakan air bersih? }\end{array}$ & 56,90 & 43,10 & 100 \\
\hline 3. & $\begin{array}{l}\text { Dilihat dari tegakan tumbuhan apakah taman KEHATI mampu } \\
\text { menahan erosi dan mencegah terjadinya banjir? }\end{array}$ & 84,48 & 15,52 & 100 \\
\hline 4. & $\begin{array}{l}\text { Dilihat dari tegakan tumbuhan apakah taman KEHATI mampu } \\
\text { menahan angin ribut/putting beliung? }\end{array}$ & 91,38 & 8,62 & 100 \\
\hline 5. & $\begin{array}{l}\text { Dilihat dari tegakan tumbuhan apakah taman KEHATI bisa } \\
\text { sebagai pembersih udara? }\end{array}$ & 87,94 & 12,06 & 100 \\
\hline 6. & $\begin{array}{l}\text { Apakah taman KEHATI mempunyai fungsi iklim mikro (faktor- } \\
\text { faktor kondisi iklim setempat yang memeberikan pengaruh } \\
\text { langsung terhadap kenikmatan (fisik) dan kenyamanan (rasa) } \\
\text { pengunjung? }\end{array}$ & 79,31 & 20,69 & 100 \\
\hline 7. & $\begin{array}{l}\text { Dilihat dari tegakan tumbuhan apakah taman KEHATI mampu } \\
\text { menahan perubahan iklim? }\end{array}$ & 58,62 & 41,38 & 100 \\
\hline & Rata-rata (\%) & 79,06 & 20,94 & 100 \\
\hline
\end{tabular}

Tabel 3 menunjukan persentase jawaban responden yang menyetujui adanya fungsi pengaturan dari taman kehati yaitu sebesar $79,06 \%$ dari total jawaban seluruh responden. Berdasarkan hasil penelitian diketahui, sebagian besar responden 94,82\% menyatakan bahwa taman KEHATI dapat menyimpan air dan hanya $44,82 \%$ dari total responden menyatakan taman KEHATI berpotensi 
untuk penyedia air bersih. Hal ini dapat kita lihat dengan adanya jenis-jenis tanaman yang terdapat di taman KEHATI, baik itu yang tumbuh secara alami maupun yang sengaja ditanam. Tanaman sangat berhubungan dengan air, tetapi hanya beberapa yang mampu menahan bahkan menyimpan air dalam jumlah besar, tanaman lokal yang berpotensi sebagai penyimpan air dan sumber air merupakan dua komponen yang secara dinamis saling berinteraksi satu sama lain, adanya keterkaitan komponen lingkungan telah ditunjukkan oleh beberapa penelitian yang dilakukan (Ulfah, 2015).

$$
\text { Responden sebesar } \quad 81,03 \%
$$
menyatakan bahwa taman KEHATI mampu sebagai penahan erosi dan mencegah terjadinya banjir dan $91,37 \%$ dari total responden bahwa taman KEHATI mampu menahan angin dan puting beliung. Hal ini dikarenakan sebagian besar responden merupakan pelajar atau mahasiwa yang tentu saja memiliki pengetahuan dan pemahaman mengenai fungsi tumbuh-tumbuhan yaitu berfungsi sebagai penahan erosi dan mencegah terjadinya banjir. Hal ini dapat kita lihat dari jenis-jenis tanaman yang terdapat di taman KEHATI, hampir seluruh tanaman tersebut memiliki akar tunggang, dimana fungsi akar tunggang untuk menyimpan air dan menyerap unsur hara dari dalam tanah serta memeperkokoh tanaman agar tidak mudah rubuh.

Mayoritas responden (87,93\%) menyatakan tumbuhan taman KEHATI sebagai pembersih udara. Sebanyak
$67,24 \%$ responden menyatakan taman KEHATI mempunyai fungsi iklim mikro dan $62,06 \%$ responden menyatakan taman KEHATI mampu menahan perubahan iklim. Tujuan dibangunnya taman KEHATI untuk penambahan tutupan lahan ruang terbuka hijau. Ruang terbuka hijau dapat meningkatkan kualitas lingkungan hidup kota, antara lain sebagai pengendali iklirn mikro, yaitu sebagai pelindung dari radiasi sinar matahari, menurunkan suhu kota, meningkatkan kelembaban udara, dan mengurangi kecepatan angin (Setyowati, 2008).

\section{Potensi Jasa Budaya (Cultural Services)}

Jasa budaya adalah jasa lingkungan sebagai identitas dan keragaman budaya, nilai-nilai religius, nilai estetika, hubungan sosial, rekreasi, dan lain-lain. Jasa budaya yang dimaksud disini berupa aktivitas yang sedang berlangsung di kawasan taman KEHATI seperti kegiatan rekreasi. Rekreasi adalah aktivitas yang dilakukan pada waktu senggang (lapang) yang bertujuan untuk membentuk, meningkatkan kembali kesegaran fisik, mental, pikiran dan daya rekreasi (baik secara individual maupun secara kelompok) yang hilang akibat aktivitas rutin sehari-hari dengan jalan mencari kesenangan, hiburan dan kesibukan yang berbeda dan memberikan kepuasan dan kegembiraan yang ditujukan bagi kepuasan lahir dan batin manusia.

Aktivitas rekreasi di taman KEHATI dapat diketahui dengan adanya pengunjung yang sedang datang 
berkunjung ke taman KEHATI yang diminta untuk mengisi kuisioner mengenai tujuan responden berkunjung, cara kedatangannya, dan pendapat mengenai taman KEHATI yaitu mengenai kelengkapan fasilitas, keadaan keamanan kawasan, mengetahui kawasan taman KEHATI merupakan kawasan pelestarian, mengetahui peraturan atau larangan yang ada dikawasan, penilaian terhadap pelayanan, dan penerangan informasi dari petugas. Serta adanya nilai pendidikan yang terdapat di taman KEHATI meliputi pembelajaran untuk membentuk jiwa konservasi terhadap suatu kawasan sehingga akan banyak terbentuk lokasi seperti taman KEHATI. Taman KEHATI juga dapat membentuk pola pikir masyarakat untuk tidak

Tabel 4. Pendapat Responden Untuk Potensi Pendukung (Opinions of Respondents for Supporting Potential)

\begin{tabular}{llccc}
\hline No. & \multicolumn{1}{c}{ Pertanyaan } & \multicolumn{2}{c}{ Jawaban } & Jumlah \\
\cline { 3 - 4 } & & Ya & Tidak & $(\%)$ \\
\hline 1. & $\begin{array}{l}\text { Apakah taman KEHATI berfungsi sebagai tempat untuk } \\
\text { bercocok tanam ? }\end{array}$ & 79,31 & 20,69 & 100 \\
\hline 2. & Apakah taman KEHATI memiliki siklus hara yang baik ? & 81,03 & 18,97 & 100 \\
\hline 3. & $\begin{array}{l}\text { Apakah taman KEHATI berfungsi sebagai tempat } \\
\text { menggembala ternak }\end{array}$ & 0 & 100 & 100 \\
\hline 4. & Apakah satwa hidup aman di taman KEHATI? & 48,28 & 51,72 & 100 \\
\hline 5 & $\begin{array}{l}\text { Apakah satwa bebas pergi dan berpindah tempat di taman } \\
\text { KEHATI? }\end{array}$ & 72,41 & 27,59 & 100 \\
\hline & Rata-rata & 56,21 & 43,79 & 100
\end{tabular}

Tabel 4 menunjukan bahwa potensi pendukung dengan total sebesar $56,21 \%$. Berdasarkan jawaban responden tersebut di atas untuk lebih jelasnya diuraikan sebagai berikut; sebesar 79,31\% responden menyatakan taman kehati berfungsi sebagai tempat untuk bercocok taman. Hal merusak lingkungan karena taman KEHATI memberikan suatu gambaran terhadap masyarakat akan banyaknya manfaat dari ekosistem alam yang belum rusak.

\section{Potensi Pendukung (Supporting Services)}

Jasa pendukung yaitu jasa yang diperlukan untuk menghasilkan semua layanan ekosistem lainnya. Fungsi jasa pendukung yaitu produksi utama, formasi tanah, produksi oksigen, ketahanan tanah, penyerbukan, ketersediaan habitat, siklus gizi dan lainlain. Guna megetahui potensi pendukung di Taman KEHATI maka responden diminta untuk menjawab beberapa pertanyaan berikut yang disajikan pada Tabel 4. 
perekonomian masyarakat, misalnya dalam pengelolaannya ketika melibatkan masyarakat, apabila sudah memasuki tahap pemanenan.

Buah-buahan tersebut bisa dijual, dan tentu saja berfungsi untuk mendukung perekonomian masyarakat. Hal ini didukung dengan tujuan dibangunnya taman KEHATI Sekadau yaitu untuk penambahan tutupan lahan ruang terbuka hijau, koleksi tumbuhan, pengembangan ilmu pengetahuan dan ekowisata serta sumber bibit dan benih. Berbeda dengan pengelolaan di taman KEHATI Gunung Kidul yang melibatkan masyarakat dalam pengelolaannya, sehingga fungsi pendukung taman KEHATI sebagai tempat untuk bercocok tanam dirasakan oleh masyarakat sekitar dan diharapkan mampu meningkatkan perekonomian masyarakat dalam hal pengembangan jasa lingkungan kedepannya seperti ekoedukasi (Fajar, 2016). Sebagian besar responden $81,03 \%$ menyatakan taman KEHATI mempunyai siklus hara yang baik. Hal ini dapat dilihat dengan adanya tumbuh-tumbuhan yang tumbuh secara alami maupun ditanam di taman. Kondisi ekosistem, hubungan tanah, tanaman, hara dan air merupakan bagian yang paling dinamis. Tanaman menyerap hara dan air dari dalam tanah untuk dipergunakan dalam proses-proses metabolisme dalam tubuhnya. Sebaliknya tanaman memberikan masukan bahan organik melalui seresah yang tertimbun dipermukaan tanah berupa daun dan ranting serta cabang yang rontok (Lisnawati, 2012).

Hasil penelitian diketahui seluruh responden menyatakan tempat ini tidak memiliki fungsi untuk menggembala ternak. Hal ini dikarenakan taman kehati merupakan kawasan pelestarian sehingga tidak memungkinkan kawasan ini dijadikan sebagai tempat untuk menggembala ternak. Keamanan satwa di taman ini sebagian besar responden $51,72 \%$ menyatakan bahwa satwa ditaman ini tidak aman, karena masih sering terjadinya perburuan liar di sekitar kawasan tersebut dan belum adanya peraturan yang jelas mengenai larangan perburuan di sekitar kawasan taman ini. Jenis satwa yang terdapat di taman KEHATI Sekadau seperti kera, musang, ular, tupai, dan terdapat beberapa jenis burung seperti, burung punai, burung prenjak, burung puyuh tegalan, burung mpuluk, burung pipit, dan lain-lain.

Responden sebesar $\quad 72,41 \%$ menyatakan satwa di taman KEHATI bebas pergi dan berpindah tempat. Hal ini karena lokasi taman kehati memiliki areal yang cukup luas yaitu \pm 23 hektar sehingga sangat mendukung satwa untuk bebas pergi dan berpindah tempat. Jenis satwa yang terdapat di taman KEHATI beberapa jenis satwa yang memiliki daya gerak arboreal yang mengacu pada sifat yang hidup di pepohonan.

\section{KESIMPULAN}

Berdasarkan hasil penelitian ini dapat disimpulkan bahwa terdapat beberapa potensi jasa lingkungan ditaman kehati yaitu :

1. Potensi jasa penyedian dapat dilihat dari adanya beberapa jenis tanaman yang memiliki potensi untuk dimanfaatkan, seperti tanaman kehutanan, buahbuahan, obat-obatan, sayuran dan kayu 
bakar. Dari berbagai jenis tanaman tersebut sebesar

2. Potensi jasa pengaturan yaitu dapat dilihat dari tegakan tumbuhan yang terdapat di kawasan tersebut, dan hasil penelitian responden menganggap taman kehati mempunyai fungsi baik itu sebagai penyimpan air, untuk menjaga kualitas udara dan lain-lain. Jika di lihat dari total keseluruhan jawaban responden sebagian besar responden menjawab ya yang berarti menyetujui bahwa taman kehati sekadau mempunyai jasa pengaturan.

3. Potensi budaya dapat diketahui dengan adanya responden yang berkunjung untuk melakukan kegiatan rekreasi wisata alam ditaman tersebut.

4. Potensi jasa pendukung yaitu dapat kita ketahui dengan berfungsinya taman kehati baik itu sebagai tempat untuk bercocok tanam, memiliki siklus hara yang baik sebesar dan mendukung sebagai tempat tinggal habitat satwa.

5. Potensi jasa lingkungan yang paling menonjol di taman KEHATI yaitu potensi penyediaan, hal ini dapat dilihat dari berbagai jenis tanaman berpotensi untuk dimanfaatkan sebagai makanan.

\section{SARAN}

1. Diharapkan taman KEHATI dapat dijaga kelestariannya dan keanekaragaman hayatinya semakin bertambah, bertambahnya keanekaragaman hayati tentu akan bertambah manfaat dari taman itu sendiri untuk masyarakat.

2. Sebaiknya perlu adanya pemberian nama/plang pada jenis-jenis tanaman yang terdapat di taman KEHATI. Hal ini bertujuan agar masyarakat yang berkunjung mudah mengenal jenis-jenis tanaman tersebut.

3. Perlu adanya partisipasi masyarakat dalam upaya mendukung pengembangan taman KEHATI, seperti menjaga kebersihan dan kelestarian kawasan tersebut agar kedepannya taman KEHATI mampu memberikan manfaat bagi masyarakat sekitar baik itu manfaat langsung berupa hasil alamnya maupun manfaat tidak langsung.

4. Sebaiknya perlu adanya penambahan jenis-jenis tanaman, karena semakin banyak jenis tanaman maka semakin banyak pula potensi jasa lingkungan yang dihasilkan oleh taman KEHATI Sekadau.

5. Potensi jasa lingkungan yang paling menonjol di taman KEHATI yaitu potensi penyediaan, hal ini dapat dilihat dari berbagai jenis tanaman berpotensi untuk dimanfaatkan sebagai makanan.

\section{DAFTAR PUSTAKA}

Fajar J. 2016. Merawat Taman Kehati Gunungkidul Dengan Hati. Berita Mongabai:1(kolom $8)$. http://www.mongabay.co.id/2016/0 6/19/merawat-taman-kehatigunungkidul-merawat-dengan-hati/

Firdaus, M. 2011. Kajian Etnibotani Tumbuhan Yang Berpotensi Sebagai Sumber Pangan Di Desa Meragun Pada Kawasan Hutan Lindung Gunung Naning Kabupaten Sekadau. (Skripsi). Fakultas Kehutanan Untan, Pontianak.

Irsyad MN, Jumari, Murningsih. 2013. Studi Etnobotani Masyarakat Desa Sukolilo Kawasan Pegunungan Kendeng Pati Jawa Tengah ( Etnhobotany Study Of Rural 
Community Sukolilo, Kendeng Mountains, Pati, Central Java) Jurnal Bioma 15(1) : 27-34.

[KLHK] Kementrian Lingkungan Hidup dan Kehutanan. 2015. 10 profil Lokasi Taman Kehati, Dalam Bina Pengelolaan Ekosistem Esensial Dirjen Konservasi Sumberdaya Alam Dan Ekosistem. Jakarta: Gedung Pusat Kehutanan Manggala Wanabakti.

Larasati MD. 2017. Pohon Ulin (Eusideroxylon Zwageri) Habitat, Sebaran, dan Status Konservasi. Berita Forester Act. (Kolom 17). https://foresteract.com/pohon-ulineusideroxylon-zwageri/

Lisnawati Y. 2012. Perubahan Hutan Alam Menjadi Hutan Tanaman Dan Pengaruhnya Terhadap Siklus Hara Dan Air. Bogor: Pusat Penelitian Dan Pengembangan Peningkatan Produktivitas Hutan Kampus Balitbang Kehutanan. Jurnal Tekno Hutan Tanaman. 5(2): 61-71.

[MEA] Millenium Ecosystem Assessment. 2005. Ecosystems and Human Wellbeing. Washington: Island press.

Sugiyono. 2013. Metode Penelitian Manajemen. Bandung: Alfabeta

Soenarno. 2014. Pembelajaran Materi Jasa Lingkungan. Jurnal Formatif 4(2): 150-151.

Setyowati DL. 2008. Iklim Mikro Dan Kebutuhan Ruang Terbuka Hijau Di Kota Semarang. Jurnal Manusia dan Lingkungan 15(3): 125-140.

Siahaan SP 2013. Uji Aktivitas Antibakteri Infusa Biji Buah Langsat (Lansium Domesticum Cor.) Terhadap Salmonella Typhi. Fakultas Kedokteran, Universitas Tanjungpura, Pontianak.
Soenarno. 2014. Pembelajaran Materi Jasa Lingkungan. Jurnal Formatif. 4(2): 150-151.

Ulfah M, Rahayu P, Dewi LR. 2015. Kajian morfologi tumbuhan pada spesies tanaman lokal berpotensi penyimpan air: Konservasi air di Karangmanggis, Boja, Kendal, Jawa Tengah. Jurnal Pros Sem Nas Masy Boidiv Indon. 1(3) : 418-422. 